\title{
THERMODYNAMIC PARAMETERS OF POTASSIUM BITARTRATE DURING THE YOUNG WINES COLD STABILIZATION
}

\author{
Ecaterina Covaci \\ Institute of Chemistry of Academy of Sciences of Moldova, 3, Academiei str., Chisinau MD-2028, Republic of Moldova \\ e-mail: covaci_ecaterina@yahoo.com; (+373) 69305475
}

\begin{abstract}
The present work was undertaken to study the effect of the treatment temperature on the potassium bitartrate stability and composition of young wines. The thermodynamic parameters, namely $\Delta G^{\circ}, \Delta H^{\circ}, \Delta S^{\circ}$ were calculated to predict the nature of potassium hydrogen tartrate (KHT) precipitation. According to the achieved results, the exothermal nature and thermodynamical feasibility of KHT precipitation in young wines were established. Based on thermodynamics, negative $\Delta G^{\circ}, \Delta H^{\circ}$ values and positive $\Delta S^{\circ}$ value give a spontaneous KHT process at lower temperatures.
\end{abstract}

Keywords: cold stabilization, tartaric salts, thermodynamic parameters, young wines.

Received: February 2015/Revised final: April 2015/ Accepted: April 2015

\section{Introduction}

Wine is a complex chemical mixture and its stability depends on the activity of microorganisms and the changes in its environment. Less than half of the found in grapes tartaric acid is free standing, the majority of it being presented as potassium acid salt (KHT, etc.). Once bottled, a wine may cause cloudiness, formation and precipitation of tartaric crystals. Under certain conditions, e.g. storage at low temperature, the dissolved form of KHT become insoluble forming small crystals, which settle to the bottom [1-3]. As it is known, for the commercial distribution of wines in bottles, the wine must not only be clear at the time of bottling, but also must remain in this condition over the time.

Numerous efficient treatment methods for the stabilization of wines are known up to now: cooling [4], cationic exchange [5-6], reverse osmosis, electro-dialysis [7] and the addition of selected additives [8-9]. From the abovementioned techniques, cooling alone has found commercial application for the tartaric stabilization of young wines. This method involves cooling the wine near its freezing point to encourage the tartrates to crystallize and precipitate out of the wine before bottling.

The present study was conducted in order to study the variation of thermodynamic parameters of KHT during the cold treatment of white and red young wines. Our efforts were also directed to the determination of some thermodynamic parameters, which describe the precipitation process at the equilibrium, such as: equilibrium constant, entropy change $\left(\Delta H^{\circ}\right)$, enthalpy change $\left(\Delta S^{\circ}\right)$ and Gibbs free energy $\left(\Delta G^{\circ}\right)$ of KHT precipitation.

\section{Materials and methods}

Investigations have been conducted on two young wines obtained from Chardonnay and Merlot varieties of vintage 2014. Experiments were carried out during September - December 2014, at the Oenology Research Centre of Technical University of Moldova. The tartrate precipitation is induced by such essential factors, as: the concentration of tartaric acid, cations and anions, $\mathrm{pH}$ value and presence of various complexing agents. The studied grapes varieties were vinified by classical technological schemas and after the alcoholic fermentation, wine samples were decanted and fined to ensure their colloidal stability. The used gluing agents for white wine was bentonite of Super type [10] at doses 0.5 $\mathrm{g} / \mathrm{L}$ and gelatin of Pulviclar S type [11] at $0.4 \mathrm{~g} / \mathrm{L}$ for the red wine, respectively. After the gluing treatment, wine samples were subjected to membrane filtration and tartaric stabilization by conventional cold stabilization at the temperature of minus $5^{\circ} \mathrm{C}$ (filtration at the seeding temperature, to avoid resolubilization of potassium bitartrate crystals into wine). Physico-chemical characteristics of the wine were evaluated by the alcohol content, total acidity, $\mathrm{pH}$ value, conductivity, content of phenolic compounds and others, using the methods presented in national and international standards [12-13] at the National Audit Centre of Alcoholic Products (Chisinau, Moldova). The content of components of studied reaction at the equilibrium - tartaric acid and potassium ions, was determined by atomic absorption spectrometry and capillary electrophoresis methods. The obtained data were used to calculate the equilibrium constant of the reaction, according to the proposed methodology [14-17].

\section{Results and discussion}

Data on the main wine composition characteristics before and after the tartaric stabilization are presented in Table 1. Colour intensity, content of tartaric acid and total polyphenol index of wine samples diminished within the limits of $23 \div 40 \%$ of the initial values during the stabilization. Content of tartaric acid and potassium has also decreased in the following order: $37.7 \%$ and $22.5 \%$ for white wine sample and $28.5 \%$ and $42.86 \%$ - for the red one, respectively. Comparative analyses of these two young wines reveal that values of all parameters decrease more significantly in the 
case of white sample. In terms of organoleptic analysis, treatment of young wines enhances the aroma expression, the flavour persistence and specific colour for the certain type of wine. The decrease in conductivity depends on the wine type, varying in our case from 318 to $331 \mu \mathrm{S}$ (Table 1).

Table 1

Physico-chemical characteristics of the wine samples.

\begin{tabular}{|c|c|c|c|c|}
\hline \multirow[b]{2}{*}{ Parameters } & \multicolumn{2}{|c|}{ Sample 1 of White wine } & \multicolumn{2}{|c|}{ Sample 2 of Red wine } \\
\hline & 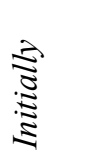 & 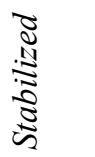 & 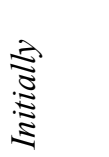 & 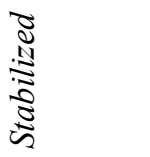 \\
\hline Ethanol $( \pm 0.06 \% \mathrm{v} / \mathrm{v})$ & 12.62 & 12.50 & 10.25 & 10.20 \\
\hline $\mathrm{pH}( \pm 0.01)$ & 3.13 & 3.08 & 3.30 & 3.20 \\
\hline Total acidity in tartaric acid $( \pm 0.04 \mathrm{~g} / \mathrm{L})$ & 7.82 & 6.80 & 8.43 & 7.62 \\
\hline Content of tartaric acid $( \pm 0.01 \mathrm{~g} / \mathrm{L})$ & 2.60 & 1.62 & 2.07 & 1.48 \\
\hline Content of potassium $( \pm 0.002 \mathrm{~g} / \mathrm{L})$ & 0.920 & 0.713 & 1.071 & 0.612 \\
\hline Colour intensity $\mathrm{A}_{420} \mathrm{~nm}( \pm 0.001)$ & 0.092 & 0.048 & 1.483 & 1.121 \\
\hline Total polyphenol index (TPI) $( \pm 0.02 \mathrm{mg} / \mathrm{L})$ & 148.8 & 86.3 & 1498.1 & 1158.3 \\
\hline Conductivity at $20^{\circ} \mathrm{C}( \pm 1 \mu \mathrm{S} / \mathrm{cm})$ & 1988 & 1670 & 2066 & 1735 \\
\hline Organoleptic analysis ( \pm 0.1 points) & 7.7 & 7.8 & 7.8 & 7.9 \\
\hline
\end{tabular}

In our opinion, in order to gain an insight into KHT precipitation process, it is absolutely necessary to take into account the thermodynamic parameters of the process such as: enthalpy, entropy and free energy. The precipitation of potassium bitatrate can be summarized by the following reversible process, which represents a heterogeneous equilibrium:

$H T^{-}+K^{+} \leftrightarrow K H T$

For determining the thermodynamic parameters of the process (1), the value of equilibrium constant of reaction is initially calculated by Eq.(2). The free energy of a precipitation process is a function of state, which is related to the equilibrium constant by the classical Van’t Hoff Eq.(3):

$K_{e q}=\frac{C_{\text {prod }}}{C_{\text {reac }}}$

$\Delta G^{\circ}=-R T \ln K_{e q}$

where: $C_{\text {prod }}$ - concentration of reaction products at equilibrium,

$C_{\text {reac }}$ - concentration of reactants in solution at equilibrium,

$\Delta G^{\circ}$ - Gibbs free energy change $\left(\mathrm{kJ} \mathrm{mol}^{-1}\right)$,

$R$ - ideal gas constant $\left(8.314 \mathrm{~J} \mathrm{~mol}^{-1} \mathrm{~K}^{-1}\right)$,

$T$ - absolute temperature (K).

Subsequently, the equilibrium constant is expressed in terms of enthalpy change of precipitation $\left(\Delta H^{\circ}\right)$ and entropy change $\left(\Delta S^{\circ}\right)$, as functions of temperature, following the Eq.(4):

$\ln K_{e q}=\frac{\Delta S^{\circ}}{R}-\frac{\Delta H^{\circ}}{R T}$

The determined thermodynamic parameters for the wine samples are presented in Table 2. For sample 1 the following $\Delta G^{o}$ values for the KHT precipitation processes at 268,273 and $278 \mathrm{~K}$ were obtained: $-6.36,-5.35$ and $-1.33 \mathrm{~kJ} \cdot \mathrm{mol}^{-1}$, respectively. These negative $\Delta G^{\circ}$ values indicate that precipitation of KHT compound onto wine is thermodynamically feasible and spontaneous. The augment of temperature induces a significant diminution of $K_{e q}$ and $\Delta G^{\circ}$ values. On the contrary, the entropy changes are well-correlated with the temperature of the system and positive entropy describes an irreversible heat flow through a system during KHT precipitation. 
Thermodynamic parameters change of the KHT precipitation reaction versus temperature for the wine samples.

\begin{tabular}{|c|c|c|c|c|}
\hline \multirow[b]{2}{*}{ Type of sample } & \multirow{2}{*}{$\begin{array}{c}\text { Temperature of } \\
\text { treatment, } \\
K\end{array}$} & \multicolumn{3}{|c|}{ Thermodynamic parameters of KHT precipitation } \\
\hline & & $\begin{array}{l}\text { Equilibrium constant, } \\
K_{e q}\end{array}$ & $\begin{array}{c}\text { Gibbs free energy, } \Delta G^{\circ}, \\
k J \cdot m^{-1}\end{array}$ & $\begin{array}{l}\text { Entropy, } \Delta S^{\circ} \\
J \cdot \mathrm{mol}^{-1} \cdot \mathrm{K}^{-1}\end{array}$ \\
\hline \multirow[t]{3}{*}{ White wine } & 268 & 17.37 & $-6.36 \pm 0.74$ & 985.74 \\
\hline & 273 & 10.54 & $-5.35 \pm 0.51$ & 978.46 \\
\hline & 278 & 1.33 & $-1.33 \pm 0.27$ & 977.88 \\
\hline \multirow[t]{3}{*}{ Red wine } & 268 & 20.90 & $-6.77 \pm 0.73$ & 627.05 \\
\hline & 273 & 12.14 & $-5.67 \pm 0.42$ & 641.52 \\
\hline & 278 & 3.17 & $-2.67 \pm 0.17$ & 604.19 \\
\hline
\end{tabular}

Temperature dependence of the KHT precipitation is associated with the studied thermodynamic parameters. In order to define the significant dependence of these parameters as a function of temperature, the Pearson correlation coefficient $\left(\mathrm{R}^{2}\right)$ was determined according to the reported method [18]. For that, graphics of dependence: $\ln K_{e q}=\mathrm{f}(1000 / \mathrm{T})$ and $\Delta G^{\circ}=\mathrm{f}(\mathrm{T})$ at the 268,273 and $278 \mathrm{~K}$ temperatures were built (Figures 1 and 2).

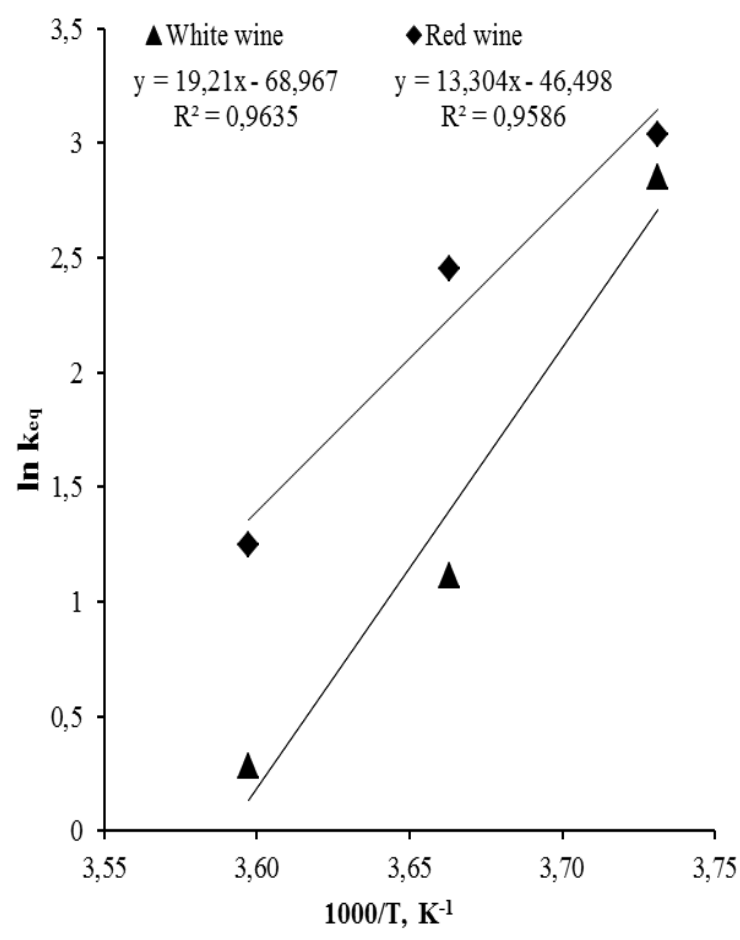

Figure 1. Van't Hoff plots for KHT precipitation at different temperatures in wine samples.

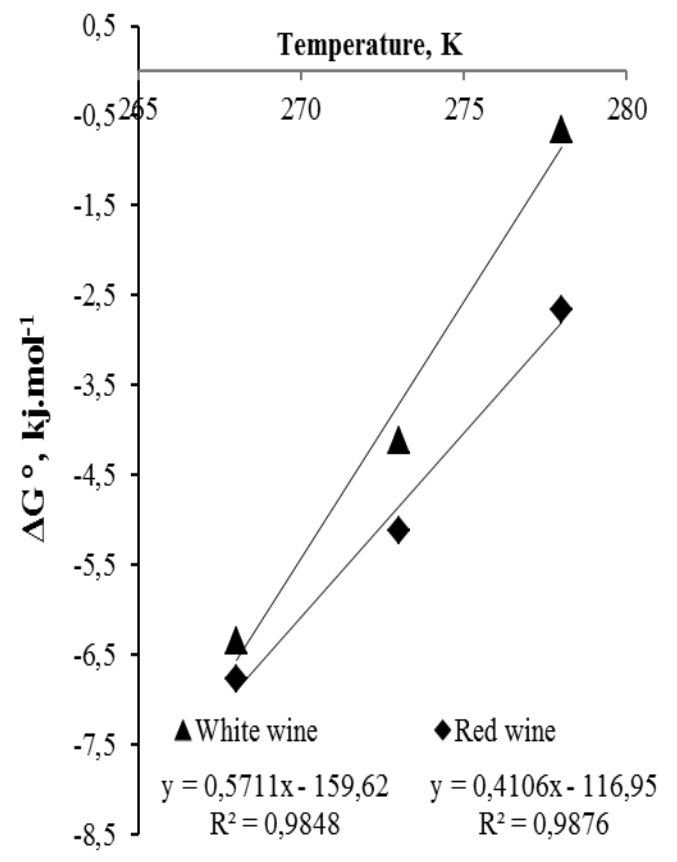

Figure 2. Gibbs plots for KHT precipitation at different temperatures in wine samples.

The values of $\Delta H^{\circ}$ were determined by using the Van't Hoff Eq. (4), the average value constituting $-263.6 \pm$ $6.9 \mathrm{~kJ} \cdot \mathrm{mol}^{-1}$ for the white wine and $-165.4 \pm 6.9 \mathrm{~kJ} \cdot \mathrm{mol}^{-1}$ for that red one, respectively. A negative value of $\Delta H^{\circ}$ expresses that the precipitation process for KHT is exothermic and the positive value of $\Delta S^{\circ}$ shows the increased randomness at the solid/solution interface during the precipitation.

The Gibbs free energy indicates on the degree of spontaneity of the KHT process and the higher negative value reflects a more energetically favourable precipitation. As depicted in Figure 2, the increase in temperature determines a significant decrease of the $\Delta G^{\circ}$ value. Also, the high value of $\mathrm{R}^{2}$ (within the limits 0.9848 and 0.9876 ) shows correctness of the selected functions and that the variance of issue parameter is attributed to the relation existing between the temperature $(\mathrm{x})$ and free energy or equilibrium constant logarithm (y). 


\section{Conclusions}

Cold stability is often considered an essential step in producing of qualitative wine. A lot of production methods are used in industry as means to cold stabilization. Often, winemakers are looking for more economical or efficient solutions for cold stabilization of wines. The study of the temperature influence on the solubility and the forms of potassium bitatrate from wines, allowed to obtain data necessary for explaining physico-chemical phenomena, which influence the stability or instability during the cold stabilization treatments, related to the precipitation of tartaric salts. Thermodynamic parameters suggested that the KHT precipitation process is spontaneous and exothermic. Also, the negative $\Delta G^{\circ}$ and $\Delta H^{\circ}$ values and positive $\Delta S^{\circ}$ values give a spontaneous process at lower temperatures with an easier KHT precipitation.

To our knowledge this is the first report on the thermodynamic study of the precipitation of potassium bitatrate in a real system (such as wine) and not in an aqueous solution.

\section{Acknowledgment}

I would like to acknowledge and express my gratitude to my scientific advisers Acad. Gheorghe Duca and Dr. hab. Rodica Sturza for the encouragement and continuous support throughout my scientific research.

\section{References}

1. Boiret, M.; Marty, A.; Fabrega, C.; Guittard, A.; Tixier, A.; Schaeffer, A.; Schlewltz, A. Tartaric stability index of wines and the risk of precipitation. Revue Française d'Oenologie, 1991, 128, pp. 53-58 (in French).

2. Dunsford, P.; Boulton, R. The kinetics of potassium bitartrate crystallization from table wines. American Journal of Enology and Viticulture, 1981, 32, pp. 106-110.

3. Mínguez, S.; Hernández, P. Tartaric stabilization of red, rose and white wines with L $(+)-$ calcium tartrate crystal seeding. American Journal of Enology and Viticulture, 1998, 49 (2), pp. 177-182.

4. Ferenczi, S.; Asvany, A.; Erczhegyi, L. Cold stabilization of wines against tartaric precipitations. Bulletin de l'OIV, 1982, 613, pp. 203-220 (in French).

5. Mira, H.; Leite, P.; Ricardo-Da-Silva, R.; Curvelo-Garcia, A. Use of ion exchange resins for tartrate wine stabilization. Journal International des Sciences de la Vigne et du Vin, 2006, 440, pp. 223-246.

6. Benitez, P.; Castro, R.; Barroso, C. Removal of iron, copper and manganese from white wines through ion exchange techniques: effects on their organoleptic characteristics and susceptibility to browning. Analytical Chimica Acta, 2002, 458, pp.197-202.

7. Gómez-Benítez, J.; Palacios-Macías, V.; Szekely-Gorostiaga, P.; Veas-López, R.; Pérez-Rodríguez, L. Comparison of electrodialysis and cold treatment on an industrial scale for tartrate stabilization of sherry wines. Journal of Food Engineering, 2003, 58, pp. 373-378.

8. Feuillat, M.; Charpentier, C. The yeast mannoproteins: a potential enological adjuvant. Bulletin de l'OIV, 1998, 813-814, pp. 945-951 (in French).

9. Moine-Ledoux, V.; Dubourdieu, D. The role of yeast mannoproteins in the tartaric stabilization of wines. Bulletin de l'OIV, 2002, 857-858, pp. 471-482 (in French).

10. Bentonit oenological (Bentonit super). http://www.protectvit.ro/cumpara/bentolit-super-bentonita-sodica / Super.htm.

11. Gelatin oenological, tip Pulviclar S. http://shop.carolinawinesupply.com/Pulviclar/PulS1.htm.

12. International Organization of Vine and Wine. International Code of Oenological Practices. Official Edition, Paris, 2012, 298 p. (in French).

13. Gerjicovoi, V. Methods of technological control in winemaking. Tavrida: Simferopol, 2009, 304 p. (in Russian).

14. Cruz, C.; Da Costa, A.; Henriques, A. Kinetic modeling and equilibrium studies during cadmium biosorption by dead Sargassum sp. Biomass. Bioresource Technology, 2004, 91, pp. 249-257.

15. Sevim, A.; Hojiyev, R.; Gül, A.; Celik, M. An investigation of the kinetics and thermodynamics of the adsorption of a cationic cobalt porphyrazine onto sepiolite. Dyes and Pigments, 2011, 88, pp. 25-38.

16. Kumar, U.; Jyotikusum, A. Thermodynamics of the Adsorption of $\mathrm{Pb}$ (II) from Aqueous Solution on NCRH. International Journal of Chemical Engineering and Applications, 2011, 2 (6), pp. 416-420.

17. Sethu, V.; Kua, Y.; Quek, W.; Lim, K.; Andresen, J. Adsorption thermodynamics of Cu (II) ions from waste water using Neem-leaf based bisorbents. Journal of Environmental Research and Development, 2011, 6, pp. 26-33.

18. Agresti, Al.; Yongyi, M. On small-sample confidence intervals for parameters in discrete distributions. Biometrics, 2001, 57 (3), pp. 963-971. 